\title{
SOME NOTES ON THE STAMMERING PROBLEM
}

BY RALPH REED, M. D.

CINCINNATI, $O$.

$\mathrm{E}$

ARLY in my work in the field of psychoanalysis, I felt that if a few stammerers were studied intensively by the psychoanalytic method, the solution of the nature of this difficulty would be readily arrived at. I still believe that psychoanalysis will answer many questions with regard to stammering, but I do not believe that it solves the problem of this disorder in anything like the complete and clean-cut way in which it has succeeded in solving the problem of many of the other psychoneuroses.

I have now investigated in greater or less psychoanalytic detail, some twenty cases of stammering. The most striking thing that to me was elucidated, was the fact that a series of stammerers will eventually contradict almost every theory that has ever been set forth, with regard to the nature of this disease. I believe that there have been more absurd and illy digested theories of stammering set forth, than with respect to almost any other psychoneurotic disorder. I studied Bleumel's Stammering and Cognate Defects of Speech, very carefully years ago, and found nothing in it of any value to me whatever. I can say the same of practically every theory of this disease that has been since advanced, including the work of both Swift and Scripture. I am unable to find that stammerers invariably possess what has been described as the stammering monotone or that their auditory memory or power of visualization is defective or that they were born lefthanded and had been trained to use the right, etc. The best summary of the stammering problem, I have yet seen, is Coriat's Stammering as a Psychoneurosis (The Journal of Abnormal Psychology, February-March, 1915).

Every stammerer certainly suffers in some degree or other from an inferiority complex, but to say this is not saying much. The mere discovery and confrontation of the patient with his inferiority complex will accomplish but little. Sometimes this seems to be the result of the stammering alone, or again it rests upon unconscious fixations that it is the duty of the psychoanalyst to unearth. Not every stammerer has been teased or made to feel humiliated by his defect; at least I have seen several who have insisted that they never suffered in this way. 
A few other facts with regard to stammering that are infrequently, if ever mentioned, may be of some interest here. Stammering does not invariably begin after the age of five or six. I saw one case in a child of three who had stammered persistently ever since she began to talk. Stammering constantly tends toward spontaneous recovery; " one rarely sees a stammerer older than thirty or forty; it is essentially a disease of adolescence. I have never yet seen a stammerer who invariably stammered on a limited and definite number of consonants, or as some prefer, vowels. A stammerer may stammer on any word or at any time. As most every one knows, stammering varies greatly on different days, even from one hour to another, but I have noted the peculiar fact that there are often certain subjunctive clauses coming in the course of a stammerer's conversation, which are spoken easily and readily. The cause of this will be later commented upon. I have not even found that a stammerer will constantly speak worse to strangers and better to friends, worse away from home and better at home, or vice versa, yet the intensity of the stammering seems to vary in the most unusual and extraordinary ways. Another point may be of interest here, as having a bearing upon what I shall later say as to the causation of stammering, and that is; if at the time of speaking an effort is required of the stammerer in some other direction than speech, he will usually speak better. If, in reading, the attention can be partially directed away from the word or phrase immediately being read, he is much more likely to read it without stammering. This is one secret of the improvement secured by stammering schools that inculcate a change of voice tone or rhythm. The attention of the stammerer is merely diverted to some extent from the essence of speech, to some secondary factor.

Of course, most stammerers can sing and speak to rhythm. I have more than once, on the first interview, considerably impressed patients by asking them to talk with the rhythm of a metronome. Frequently this is a discovery to them, as they had not previously known this to be possible. But as some one has aptly put it; the stammerer cannot go about for the rest of his life, beating time to his conversation. I may say that I have tried various methods of correcting stammering by rhythm, change of modulation, etc., and nothing now remains except to condemn them one and all, absolutely and com-

Individuals who have stammered will usually rationalize their recovery. They at tribute it to one factor or another, sometimes their own "will power." I believe that actual attainment in other directions has the most important influence. 
pletely. It may be well enough to remark here that in my opinion, the one thing to avoid in treating the stammerer, is the directing of his attention in any way whatever, to his speech per se.

After all, there does not seem to me to be any profound mystery in the stammering problem. Of course, as every one know's, the stammerer can speak as well as any one else, as is evidenced by the fact that very frequently he does speak with ease and fluency. Stammering is not essentially a speech defect at all, any more than writer's cramp constitutes an essential deficiency in the ability to write. The only reason that the stammerer does not recover with the same readiness that the victim of writer's cramp recovers, is because he cannot, as the patient with writer's cramp can, forego the effort to speak for a sufficiently long period of time to give him the opportunity of regaining his speech confidence. But this is not to say that stammering is alone a mere habit fear. It is very much that, to be sure, but it is also a true anxiety neurosis, dependent upon a complex group of unconscious factors.

The essential physical mechanism of stammering, I believe, is nothing more than an undue amount of energy overflowing into the muscles of speech. If I attempt to pick up my pen from the desk, it is obvious that if I do not put sufficient energy into the muscles of the fingers and hand the pen will fall from my grasp. It is equally obvious that if I put forth too much energy the hand will become cramped and something in the nature of a spasm be manifested. The exact amount of energy necessary to speech is much more subtly determined than in grasping an object. The same thing happens in w'riter's cramp. This also explains why the stammerer frequently can whisper, but cannot speak in an ordinary tone. He simply over-energizes his speech. This is why, if some of this energy can be diverted, he can speak with freedom; and why, with subordinate clauses or inconsequential remarks, he is much more likely to speak with ease; and again why, on talking over the telephone or giving his name, stammering is more pronounced. The more important the thought he desires to utter, naturally the more certain the speech defect manifests itself since he, because of anxiety, directs more energy toward the physical mechanism of specch. ${ }^{2}$

'Since writing the above a woman aged 48 has come under my care suffering from a complication of nervous symptoms. She has a marked winking tic. From the age of eight to eleven, her mother informs me, she was a bad stammerer. Her parents "broke" her of the habit. But immediately the tic developed and has remained with her ever since. 
As has been previously noted, stammering seems to possess many features in common with writer's cramp, blushing neurosis and other situation phobias. The next related nervous state, to the former, is any excessive reaction in the presence of strangers, in the simplest form, ordinary bashfulness. This frequently is manifested in such an extreme degree as to constitute a true psychoneurosis. We thus see that we can trace a red line of relationship from stammering through several types of psychoneurosis, to the simple bashfulness so commonly observed in children.

Writer's cramp may be regarded as resting upon the same general basis, although I have no doubt that at times it may be traced to some specific inhibition to writing itself. In a recent case I analyzed, I found the following series of incidents that preceded an attack of telegrapher's cramp. I was not consulted for the relief of this condition, as it constituted a bit of ancient history in the case. This man remembered a very vivid dream that he had had during his adolescent years. It showed clearly a marked castration fantasy and after waking, it was some time before he could convince himself that this had not happened to him. Some years later, after an abdominal operation, when he came out from the anesthetic, he thought that his right hand had been amputated and insisted to the nurse that this was the case. She held his hand before his face and attempted to convince him that this was not so, but it was several hours after waking, before he could convince himself. Some time following this, while working as a telegrapher, he fell asleep late one night and had the following dream: He thought that a dog had bitten or scratched a hole clear through the palm of his right hand. He awoke with a marked feeling of anxiety. Thus it can hardly be doubted that the telegrapher's cramp which developed very soon after that, had for its origin a definite right hand association. Thus stammering; writer's cramp; telegrapher's cramp; piano-player's cramp, morbid blushing and even tic, would seem to be related.

However, I do not believe that all cases of writer's or telegrapher's cramp would admit of any such specific analysis, and I believe that we can easily concede that an habitual speech cramp or spasm might have an even more general origin, since speech constitutes a more nearly complete expression of one's whole personality.

Might not any factor tending to produce an inferiority complex or an introverted attitude, favor the production of the stammering psychoneurosis? I have investigated carefully, the ordinary early 
possible associations and fixations one might naturally suppose would be productive of stammering and so far, I have been unable to trace any particular stammerer's difficulty to any special incident.

For instance, the chance that stammering represents an inhibition against the utterance of obscene words, or that stammerers as very young children might have been over-corrected on the occasion of an indulgence in obscene language, or have had their mouths washed out with soap and water, etc., - no such incidents have been found in any of my cases. Neither have I found any word association, such as the name of an individual member of the family, or childhood associate connected with sexual incidents productive of types of early neurotic fixation resulting in a tendency to stammer on the same letters with which these names began. But Coriat relates what seems to be a rather convincing case of this sort.

I believe it is difficult to note the continued improvement and cure of stammering, while the patient is under treatment. The simple reason for this seems to be that the treatment itself, because of the very fact that the patient knows that it is being taken for the cure of stammering, draws sufficient attention to speech itself to prevent a recovery.

Speech is largely emotional in origin and essentially automatic, and hence, like other automatic actions, is carried out with the greatest facility when the attention is distracted to something else. We talk best when we are thinking clearly and accurately of what we want to say, rather than when we are confronting ourselves with how it is being said. This is the stammerer's barrier. He can never forget, consciously or unconsciously, what he considers to be the necessity for speech effort. A million associations with speech failure have determined this. Now one or two observations on therapy.

There seems to be a general conspiracy to impress the stammerer with the seriousness of his disability. This, I believe, is a grave mistake. Compared to many other disabilities, even to other psychoneuroses, stammering does not constitute the serious disorder that stammerers are led, in many ways, to believe. One of the first steps in undertaking the treatment of a case of stammering, must therefore be the elimination, as far as this is possible, from the mind of the stammerer of all concern with regard to his speech defect. I usually spend one or two hours on this point alone, in beginning treatment. I always insist that he must not expect an early cure. This, I believe to be very important. If the stammerer is constantly looking for improvement, 
to that degree his attention is being constantly directed toward his speech. I tell him that when the treatment is ended, there will probably be no special change whatever to be noted in his speech. It will be readily seen that this is a decided about-face from all so called therapeutic suggestion. In fact I go even further and attempt to assist the stammerer to a state of mind toward his disorder, wherein he becomes utterly indifferent as to whether he ever recovers or not. It took a number of failures and merely partial successes, in the treatment of stammering, to bring me radically to this point of view. I attempt to inculcate the idea with the stammerer that his stammering, after all, is of slight consequence, that it troubles him much more than it does any one else and that no matter what calling in life or ambitions he may have, he need not fear that the stammering will interfere in the slightest with their attainment. I cite incidents of men of marked prominence and success, whom I have known, who were stammerers. After a few interviews, my patient is usually able, with a fair degree of success, to accept this point of view and I may say that the attitude of confidence and freedom gained, constitutes in itself a marked relief of his previous feeling of inferiority and distrust of himself.

These preliminary steps having been taken, it next becomes necessary to point out to the patient that the stammering is probably nothing more than merely one symptom of a general neurotic and introverted personality, that should be corrected and that it is this, perhaps as much as the stammering in itself, that has held him back from the attainment of his ambitions. This prepares his mind for the general psychoanalytic investigation that should follow. When this is undertaken, it will actually be found that the stammerer often preserves many types of infantile reaction and that his relationship to some member of his family is not truly normal. I often find an older brother, or sister, or father, or mother who is still dominating the patient to an extreme degree and, therefore, he has never succeeded in attaining complete adult expression, but is still infantile in his feelings and reactions toward the other individual. This usually tends strongly to maintain his general inferiority complex.

With respect to the dominating individual, imitative factors may enter. For instance, in one of my cases, a girl of twenty-two had always been made to feel very inferior to an older, prettier and more socially successful sister. At the same time, all of her ambitions and longings for freedom were markedly restricted by a narrow and puritanical mother, who prevented all self assertion that the older sister 
did not prevent, and did all she could to keep this girl a mere child, without initiative or will of her own. The mother had the most intense and rapid manner of speech that I think I have ever listened to.

Although this case had a very intensive analysis, she showed but little improvement until she acquired the strength of will to break, amicably but completely, with her family and accept a position in a city that was as far away as she could get, from the city in which her family resided.

The psychoanalysis having been concluded, the patient is dismissed without further reference to his speech and told to report in six months or a year. By this time, new adjustments should have been effected and a definite improvement is usually to be noted. The patient has ordinarily lost all interest in his speech disability and is not tempted to further efforts at cure, such as the patronizing of advertising stammering schools or other psychological quackery.

Thus the conclusion of the whole matter, to my mind, is simply that the problem of stammering will admit of no special solution, but must be worked out on the basis of each individual case; with special reference to the thought that all attention directed toward the speech mechanism in itself is definitely contra-indicated. This at least eliminates one hundred and one foolish and futile theories of stammering therapy. 